\title{
Norfloxacin, a Fluoroquinolone Antibiotic, Inhibits Langerhans Cell-Mediated Th1 and Th2 Cell Development
}

\author{
Katsuhiko Matsui, Azusa Kashima, Ayaka Motegi \\ Department of Clinical Immunology, Meiji Pharmaceutical University, Tokyo, Japan. \\ Received, December 26, 2018; Revised February 6, 2019; Accepted, April 2, 2019; Published, April 5, 2019.
}

\begin{abstract}
Background: It is widely acknowledged that Langerhans cells (LCs) play a primary role in the polarization of T helper type 1 (Th1) or T helper type 2 (Th2) immune responses. Our aim was to find fluoroquinolone ("new quinolone") antibiotics that would inhibit LC-mediated Th2 cell development. Methods: Expression of LC surface molecules was investigated using the reverse transcriptase polymerase chain reaction. The effects of fluoroquinolone antibiotics on T-cell immunoglobulin and mucin domain-containing protein (TIM)-4 expression in LCs were examined to predict whether they would inhibit Th2 cell development. Mice were primed via the hind footpad with ovalbumin (OVA) peptide-pulsed LCs that had been treated with a selected fluoroquinolone antibiotic, then 5 days later the cytokine response in popliteal lymph nodes was examined by enzyme-linked immunosorbent assay. Results: Norfloxacin was selected as a candidate inhibitor of Th2 cell development. As expected, OVA peptide-pulsed LCs that had been treated with norfloxacin and injected into the hind footpads of mice inhibited Th2 cell development, as represented by down-regulation of interleukin (IL)- 4 production, as well as Th1 cell development, as represented by down-regulation of interferon (IFN)- $\gamma$ production. This additional inhibition of Th1 cell development was accompanied by suppression of CD40 expression in LCs. In addition, Staphylococcus aureus strains isolated from skin lesions of patients with atopic dermatitis (AD) were more susceptible to norfloxacin than to gentamicin. Topical treatment with norfloxacin significantly suppressed the increase in the skin severity score in $\mathrm{NC} / \mathrm{Nga}$ mice with $\mathrm{AD}$-like skin lesions. This suppressive effect was associated with a decrease in the production of IFN- $\gamma$ and IL-4 in auricular lymph node cells. Conclusions: The present results show that topical application of norfloxacin inhibits the development of AD-like skin lesions in NC/Nga mice. This suggests that topical application of norfloxacin to AD lesions colonized with $S$. aureus would act on both superficial $S$. aureus and epidermal LCs, thus possibly inhibiting the development of Th1 and Th2 cells in vivo, and controlling the severity of AD.
\end{abstract}

\section{INTRODUCTION}

Atopic dermatitis (AD) is a chronic inflammatory skin disease with immunopathologic features that vary depending on the duration of the lesions. Most AD patients show superficial skin colonization by Staphylococcus aureus and increased expression of T helper type 2 (Th2) cytokines such as interleukin (IL)-4, IL-5 and IL-13 in their peripheral blood mononuclear cells (1). S. aureus can be isolated from $96-100 \%$ of $\mathrm{AD}$ skin lesions, whereas only $0-10 \%$ of healthy individuals show skin colonization by this organism $(2,3)$. We have also found that $S$. aureus is detected more frequently in the lesioned skin of AD patients than in non-lesioned skin, and that the $S$. aureus bacterial cell count is significantly higher in the former than in the latter (3). Furthermore, we have recently demonstrated that chronic $S$. aureus skin colonization may enhance $\mathrm{Th} 2$ cell development in AD patients (4-6). Therefore, treatment with antibiotics may be beneficial for AD patients, not only those with impetiginized $\mathrm{AD}$ but also those without clinical signs of superinfection.

Langerhans cells (LCs) are a subpopulation of bone marrow-derived dendritic cells (DCs). They are antigen-presenting cells (APCs), capable of internalizing and processing antigen (7). Because LCs reside in the epithelium of the skin and mucosal membranes, they act as primary response cells for antigens entering the skin, oral mucosa and airways (8-11). After uptake of antigen, they migrate to regional lymph nodes where peptides, in the context of major histocompatibility complex (MHC) class II molecules, are presented to naïve Th cells bearing appropriate Th cell receptors. This initial signal, together with a second signal delivered in part by interaction between the CD80 and CD86 molecules on LCs and CD28 on Th

Corresponding Author: Katsuhiko Matsui, Ph.D., Department of Clinical Immunology, Meiji Pharmaceutical University, 2-522-1 Noshio, Kiyose, Tokyo 204-8588, Japan; E-mail: kmatsui@my-pharm.ac.jp 
cells, results in activation of the Th cells $(12,13)$. Furthermore, LCs are the primary orchestrators of polarization towards a Th1 or a Th2 immune response under the influence of a number of factors, particularly Th2 cytokines produced by Th2 cells, thus playing a pivotal role in the induction of allergic inflammation (14). This suggests that allergic inflammation might be controllable through regulation of LCs. We have previously succeeded in generating LCs from murine bone marrow and used them to develop Th1 cells or Th2 cells (15). Although some fluoroquinolone ("new quinolone") antibiotics are known to have immunomodulatory effects in addition to bactericidal activity (16), it is unclear whether they inhibit Th2 cell development mediated by LCs. In the present study, we investigated the effects of fluoroquinolone antibiotics on LCs to inhibit Th2 cell development and evaluated the effect of topical application of a selected antibiotic on AD-like skin lesions in NC/Nga mice.

\section{MATERIALS AND METHODS}

\section{Mice}

Specific-pathogen-free BALB/c (wild type) mice and $\mathrm{NC} / \mathrm{Nga}$ mice were obtained from Japan SLC (Hamamatsu, Japan) and DO 11.10 TCR Tg mice

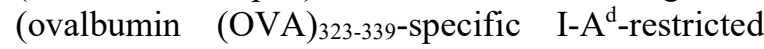
T-cell receptor (TCR)-transgenic mice) were obtained from the Jackson Laboratory (Bar Harbor, ME, USA), and used at the age of 6 to 8 weeks. They were housed in plastic cages with sterilized paper bedding in a clean, air-conditioned room at $24{ }^{\circ} \mathrm{C}$ and allowed free access to a standard laboratory diet and water. All procedures performed on the mice were in accordance with the Guidelines of the Animal Care and Use Committee of Meiji Pharmaceutical University, Tokyo.

\section{Antibiotics}

Norfloxacin, ofloxacin, ciprofloxacin, lomefloxacin, tosufloxacin, levofloxacin, prulifloxacin, pazufloxacin and moxifloxacin were purchased from Sigma-Aldrich (St. Louis, MO, USA).

\section{Generation of LCs}

Mouse bone marrow cells for generation of LCs were prepared and cultured as described previously (15). Briefly, bone marrow cells from BALB/c mice were cultured in RPMI 10 (RPMI 1640 medium with L-glutamine (Sigma-Aldrich) containing $10 \%$ fetal bovine serum (Sigma-Aldrich), $25 \mathrm{mM}$ Hepes (Sigma-Aldrich), $100 \mathrm{U} / \mathrm{mL}$ penicillin and $100 \mu \mathrm{g} / \mathrm{mL}$ streptomycin
(Gibco RBL, Grand Island, NY, USA)) supplemented with recombinant murine GM-CSF (20 ng/mL; PeproTech, Rocky Hill, NJ, USA), recombinant murine IL-4 (100 ng/mL; PeproTech) and recombinant human TGF- $\beta 1 \quad(10 \mathrm{ng} / \mathrm{mL}$; PeproTech) at $37{ }^{\circ} \mathrm{C}$ in a humidified atmosphere with $5 \% \mathrm{CO}_{2}$. Half the total volume of the culture medium was changed every $48 \mathrm{~h}$, and 7 days after the start of culture, the grown cells were treated with mouse anti-mouse I-A ${ }^{\mathrm{d}}$ monoclonal antibody (clone 34-5-3s, mouse IgG2a) (a final concentration of 1: 200; Cedarlane Laboratories Ltd., Ontario, Canada) in RPMI 10 for $1 \mathrm{~h}$ on ice. The cells that had reacted with the anti-I- $\mathrm{A}^{\mathrm{d}}$ antibody were then purified using a CELLection Pan Mouse IgG Kit (Invitrogen Dynal AS, Oslo, Norway), and used as LCs. LCs positive for I-A ${ }^{\mathrm{d}}$ were purified to around $95 \%$ purity as determined by flow cytometry.

\section{Reverse Transcription-Polymerase Chain Reaction Assay (RT-PCR)}

To determine the levels of mRNA expression for various cell surface molecules, mRNA was extracted from LCs $\left(1 \times 10^{5}\right.$ cells $)$ using a Dynabeads mRNA DIRECT Micro Kit (Life Technologies, Oslo, Norway). The cDNA was then synthesized from $160 \mathrm{ng}$ of the mRNA using a first-strand cDNA synthesis kit (GE Healthcare UK Ltd., Little Chalfont, Buckinghamshire, UK). PCR was performed using the following primers: $\beta$-actin $\left(540 \quad\right.$ bp) $\quad 5^{\prime} \quad$ primer, 5'-GTGGGCCGCTCTAGGCACCAA-3' and 3' primer,5'-CTCTTTGATGTCACGCACGATTTC-3 '; T-cell immunoglobulin and mucin domain-containing protein (TIM)-4 (304 bp) $5^{\prime}$ primer, 5'-GTCCAGTTTGGTGAAGTGTC-3' and 3' primer, 5'-ACGTGGTCACTGCTGTACTG-3';

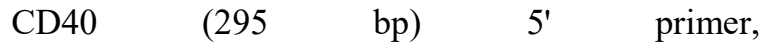
5'-CCTGTAAGGAAGGACAACAC-3' and 3' primer, 5'-ATCACGACAGGAATGACCAG-3'; CD80 (312 bp) $55^{\prime}$ primer, 5'-GAAGACCGAATCTACTGGCA-3' and 3' primer, 5'-GGAAGCAAAGCAGGTAATCC-3'; $\begin{array}{llll}\text { CD86 (302 bp) } & \text { 5' } & \text { primer, }\end{array}$ 5'-AGCCTGAGTGAGCTGGTAGT-3' and 3' primer, 5'-CCTGTTACATTCTGAGCCAG-3';

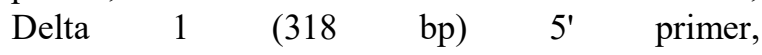
5'-TGCACTGACCCAATCTGTCT-3' and 3' primer, 5'-CTCACAGTTGGCACCTGTAT-3';

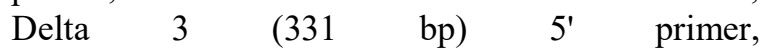
5'-CTACTGTGAAGAGCCTGATG-3' and 3' primer, 5'-ACAGACATAGGCAGAGTCAG-3'; $\begin{array}{lllll}\text { Delta } 4 & (307 & \text { bp }) & 5 & \text { primer, }\end{array}$ 5'-TCACCAGACTGAGCTACTCT-3' and 3' primer, 5'-ATGCTGCAGGTGCCATGGAT-3'. 
Each PCR was performed using a GeneAmp PCR System 9700 (Perkin-Elmer, Norwalk, CT, USA) in $25 \mu \mathrm{L}$ of reaction mixture comprising $1.5 \mu \mathrm{L}$ cDNA (corresponding to $16 \mathrm{ng}$ of mRNA starting material), $200 \mu \mathrm{M}$ deoxynucleotide triphosphate mixture, $400 \mathrm{nM}$ each PCR primer and $25 \mathrm{U} / \mathrm{mL}$ Ex Taq DNA polymerase (Takara, Shiga, Japan). The reaction conditions were as follows: one 4-min cycle at $94{ }^{\circ} \mathrm{C}, 35$ cycles comprising $45 \mathrm{~s}$ at $94{ }^{\circ} \mathrm{C}$, $45 \mathrm{~s}$ at $61^{\circ} \mathrm{C}$ and $2 \mathrm{~min}$ at $72{ }^{\circ} \mathrm{C}$, followed by one 7 -min cycle at $72{ }^{\circ} \mathrm{C}$, and the PCR products were separated on a $2 \%$ agarose gel containing ethidium bromide. The data were shown as the representative results of four independent experiments.

Th1 Cell and Th2 Cell Regulation by Antibiotic-Treated LCs

Th1/Th2 regulation by LCs was investigated as described previously (17). Briefly, LCs were adjusted to $2 \times 10^{5}$ cells $/ \mathrm{mL}$ in RPMI 10 and then incubated with $6 \mu \mathrm{M}$ OVA peptide (323-ISQAVHAAHAEINEAGR-339; obtained from Operon Biotechnologies, Tokyo, Japan) in the presence or absence of $5-50 \mu \mathrm{M}$ each fluoroquinolone antibiotic at $37^{\circ} \mathrm{C}$ in a humidified atmosphere with $5 \% \mathrm{CO}_{2}$. The cells were collected after incubation for $18 \mathrm{~h}$, washed in RPMI 10, and injected at a dose of $5 \times 10^{4}$ cells into both hind footpads of DO 11.10 TCR Tg mice. After 5 days, popliteal lymph nodes were harvested and adjusted to $1 \times 10^{6}$ cells $/ \mathrm{mL}$ in RPMI 10 . The cultures $(0.2$ $\mathrm{mL} /$ well) were incubated in 96-well culture plates (Nunc, Roskilde, Denmark) in the presence of Dynabeads Mouse T-Activator CD3/CD28 (5 $\mu \mathrm{L} /$ well; Life Technologies, Oslo, Norway) at $37^{\circ} \mathrm{C}$ in a humidified atmosphere with $5 \% \mathrm{CO}_{2}$. The culture supernatants were collected after incubation for $48 \mathrm{~h}$, and the concentrations of interferon (IFN)- $\gamma$ and IL-4 were measured using enzyme-linked immunosorbent assay (ELISA) kits for quantification of murine IFN- $\gamma$ and IL-4, respectively ( $\mathrm{R} \& \mathrm{D}$ Systems, Minneapolis, MN, USA). The results were expressed as means $\pm \mathrm{SD}$ $(n=6)$.

\section{Antibiotic Sensitivity Test}

$S$. aureus strains were isolated from the lesional skin of AD patients, and the antibiotic sensitivity of each strain was measured as the minimum inhibitory concentration (MIC). The MIC for each antibiotic was determined by the broth microdilution method using Mueller Hinton broth, as recommended by the Japanese Society of
Chemotherapy. The numbers of $S$. aureus strains affected at each MIC were expressed as a percentage of the 33 strains overall.

Topical Application of Norfloxacin to NC/Nga Mice with AD-Like Skin Lesions and Measurement of Skin Severity Score

AD-like skin lesions in $\mathrm{NC} / \mathrm{Nga}$ mice were produced and the therapeutic effects of norfloxacin were assessed by measurement of the skin severity scores as previously described (18). Briefly, the abdominal hair of NC/Nga mice was shaved, then $100 \mu \mathrm{L}$ of $5 \% \quad 2$, 4, 6-Trinitrochlorobenzene (TNCB) dissolved in an ethanol and acetone mixture (4:1) was applied topically to the abdominal skin $\left(80 \mu \mathrm{L} / 8 \mathrm{~cm}^{2}\right.$ skin) and hind footpads $(10 \mu \mathrm{L} /$ each footpad). Four days after sensitization, the dorsal side of the ears $(10$ $\mu \mathrm{L} /$ each ear) and the shaved dorsal skin $(80 \mu \mathrm{L} / 8$ $\mathrm{cm}^{2}$ skin) were challenged with $100 \mu \mathrm{L}$ of $0.8 \%$ TNCB dissolved in an olive oil and acetone mixture (4:1). After the first challenge, $0.8 \%$ TNCB was repeatedly applied to the same area of the skin a further 5 times at intervals of 1 week. After 4 days of the second $0.8 \%$ TNCB challenge, vehicle, $0.1 \%(\mathrm{w} / \mathrm{w})$ betamethasone ointment and $0.1 \%(\mathrm{w} / \mathrm{w})$ norfloxacin ointment were applied topically to the dorsal side of the ears and the dorsal skin $\left(50 \mathrm{mg} /\right.$ body $\left[=50 \mathrm{mg} / 10 \mathrm{~cm}^{2}\right.$ skin] $)$ in each group once per day for a total of 29 days. TNCB and betamethasone were purchased from Tokyo Chemical Industry (Tokyo, Japan). White petrolatum including $5 \%(\mathrm{w} / \mathrm{w})$ liquid paraffin was used as the vehicle, and betamethasone ointment and norfloxacin ointment were prepared. The drug concentration in ointments was equal to that used in clinical practice. The severity of dermatitis was assessed macroscopically according to the scoring system described below. One skin lesion on each ear, and one on the back, were scored on the basis of the following criteria. The dermatitis score (minimum 0 ; maximum 30 [ $=3$ regions $\times 2$ points $\times 5$ symptoms]) was defined as the sum of the individual scores for the three regions, and graded as 0 (no symptoms), 1 (less than $1 / 3$ of the skin area) or 2 (1/3 and more of the skin area), for each of the following 5 symptoms: redness/scratch marks, edema/lichenification/thickening, hemorrhage/scabbing, erosion, and desquamation. The results for each experimental group were expressed as means $\pm \operatorname{SD}(n=6)$. 
Quantification of Th1 and Th2 Cytokine Production from $T$ Lymphocytes in Lymph Nodes

Auricular lymph node cells were harvested on the 29th day of assessment of skin severity, and adjusted to $1 \times 10^{6}$ cells $/ \mathrm{mL}$ in RPMI 10 . The cultures $(0.2 \mathrm{~mL} /$ well $)$ were incubated in 96 -well culture plates (Nunc) in the presence of Dynabeads Mouse T-Activator CD3/CD28 (Life Technologies) at $37^{\circ} \mathrm{C}$ in a humidified atmosphere with $5 \% \mathrm{CO}_{2}$. The culture supernatants were collected after incubation for $48 \mathrm{~h}$, and the IFN- $\gamma$ and IL-4 concentrations were measured using ELISA kits for quantification of murine IFN- $\gamma$ and IL-4, respectively (R \& D Systems). Each culture was prepared in triplicate, and the mean value was obtained as a representative result for one experiment. The results were expressed as means \pm $\operatorname{SD}(n=6)$.

\section{STATISTICAL ANALYSIS}

The data were expressed as means ( \pm SD), and differences between means were analyzed by Tukey-Kramer's multiple comparison test. Differences at $P<0.05$ were considered to be statistically significant.

\section{RESULTS}

Effects of Fluoroquinolone Antibiotics on TIM-4 mRNA Expression in LCs

In order to predict the inhibitory effects of fluoroquinolone antibiotics on Th2 cell development, we examined their influence on TIM-4 expression in LCs. LCs were pulsed with OVA peptide for $18 \mathrm{~h}$ in the presence or absence of norfloxacin, ofloxacin, ciprofloxacin, lomefloxacin, tosufloxacin, levofloxacin, prulifloxacin, pazufloxacin and moxifloxacin, respectively, and expression of mRNA for a cell surface molecule, TIM-4, was investigated using RT-PCR. As shown in Figure 1, since it was confirmed that norfloxacin, but not other antibiotics, inhibited the expression of TIM-4 mRNA in LCs, norfloxacin was selected as a candidate inhibitor of Th2 cell development.

\section{Effects of Norfloxacin on Th1 Cell and Th2 Cell Development through LCs}

LCs were pulsed with OVA peptide for $18 \mathrm{~h}$ in the presence or absence of norfloxacin. The LCs were then washed and injected into the hind footpads of DO 11.10 TCR Tg mice, and 5 days later draining popliteal lymph node cells were harvested. T-lymphocytes among the lymph node cells were stimulated for $48 \mathrm{~h}$ through their surface $\mathrm{CD} 3 / \mathrm{CD} 28$ molecules, and the concentrations of IFN- $\gamma$ and IL- 4 in the culture supernatants were determined by ELISA. As shown in Figure 2, LCs treated with norfloxacin showed dose-dependent inhibition of Th2 cell development, as represented by suppression of IL-4 $\square$ production. Norfloxacin also dose-dependently inhibited Th1 cell development as represented by suppression of IFN- $\gamma$ production.

\section{Effects of Norfloxacin on Expression of mRNA for Cell Surface Molecules in LCs}

In order to clarify the mechanisms responsible for regulation of Th1 cell development via norfloxacin-treated LCs, LCs were pulsed with OVA peptide for $18 \mathrm{~h}$ in the presence or absence of norfloxacin, and expression of mRNA for the cell surface molecules CD40, CD80, CD86, Delta 1, Delta 3 and Delta4 was investigated using RT-PCR. As shown in Figure 3, LCs treated with norfloxacin inhibited the expression of CD40 mRNA, but did not influence that of other mRNAs.

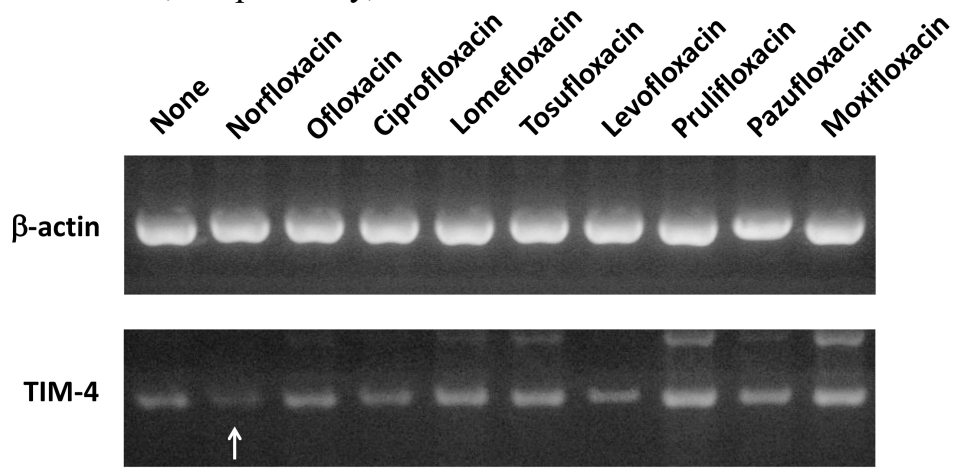

Figure 1. Effects of fluoroquinolone antibiotics on expression of TIM-4 mRNA in LCs. LCs were pulsed with OVA peptide for $18 \mathrm{~h}$ in the presence or absence of each antibiotic (50 $\mathrm{MM}$; an optimal concentration). Cytoplasmic mRNA was extracted from the LCs, reverse-transcribed, and amplified by PCR using $\beta$-actin and TIM- 4 primer sets. The data shown are the representative results of four independent experiments. 

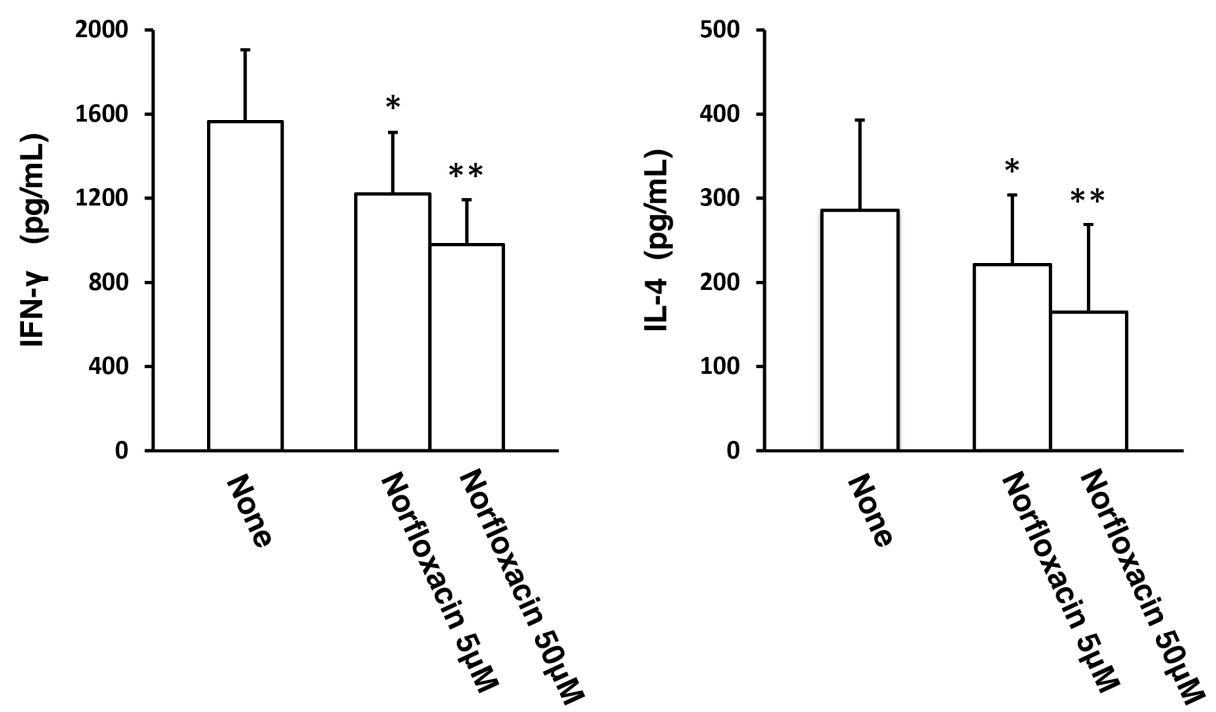

Figure 2. Effects of norfloxacin on Th1 and Th2 cytokine production from lymph node T-lymphocytes. LCs were pulsed with OVA peptide for $18 \mathrm{~h}$ in the presence or absence of 5-50 $\mu \mathrm{M}$ norfloxacin. The OVA peptide-pulsed LCs were injected into the hind footpads of mice, and lymph node cells were harvested 5 days later. The lymph node cells were stimulated through their surface CD3/CD28 molecules, and the concentrations of IFN- $\gamma$ and IL-4 in the culture supernatants were determined by ELISA. The results are expressed as means $\pm \mathrm{SD}(\mathrm{n}=6)$.

$* P<0.05,{ }^{*} * P<0.01$ versus non-treatment.

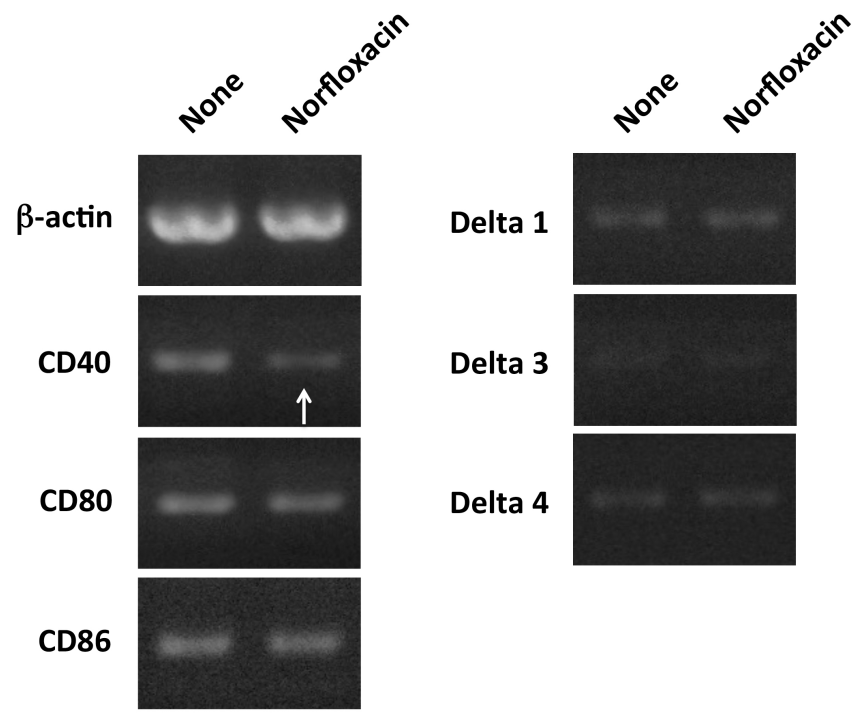

Figure 3. Effects of norfloxacin on expression of cell surface molecule mRNA in LCs. LCs were pulsed with OVA peptide for $18 \mathrm{~h}$ in the presence or absence of $50 \mu \mathrm{M}$ norfloxacin. Cytoplasmic mRNA was extracted from the LCs, reverse-transcribed, and amplified by PCR using primer sets for $\beta$-actin, CD40, CD80, CD86, Delta 1, Delta 3 and Delta 4. The data shown are the representative results of four independent experiments.

\section{Susceptibility of $S$. aureus Strains to Gentamicin and Norfloxacin}

The gentamicin and norfloxacin susceptibility of $S$. aureus strains isolated from the lesional skin of $\mathrm{AD}$ patients was also investigated. Figure 4 shows that $87.9 \%(29 / 33)$ of $S$. aureus strains were markedly susceptible to norfloxacin, whereas gentamicin showed lower antibacterial activity.
Effects of Topical Application of Norfloxacin on AD-Like Skin Lesions and Production of IFN- $\gamma$ and IL-4

Assessment of skin lesion severity in NC/Nga mice sensitized with 5\% TNCB was started 4 days after the second challenge with $0.8 \%$ TNCB. The clinical skin lesion severity in the TNCB-sensitized mice increased gradually with time (Figure 5). All 
mice in the positive control group (TNCB only) exhibited AD-like skin lesions comprising redness / scratch marks, edema / lichenification/thickening, hemorrhage/scabbing, erosion and desquamation. However, in the negative control mice (untreated), no superficial lesions were observed throughout the experimental period. After 8 days of assessment, the therapeutic efficacy of $0.1 \%$ norfloxacin ointment became apparent and persisted throughout the experimental period, its efficacy being approximately equal to that of $0.1 \%$ betamethasone ointment. However, topical application of vehicle only had no effect on the development of dermatitis.

Subsequently, in order to examine Th1 and Th2 cell development in auricular lymph node on the 29th day of assessment of skin severity, ELISA for IFN- $\gamma$ and IL-4 was carried out using culture supernatants of lymph node cells stimulated through surface CD3/CD28 molecules for $48 \mathrm{~h}$. Figure 6 shows that IFN- $\gamma$ and IL-4 production from lymph node cells was significantly increased by TNCB treatment and suppressed by treatment with norfloxacin as well as betamethasone, but not by vehicle.

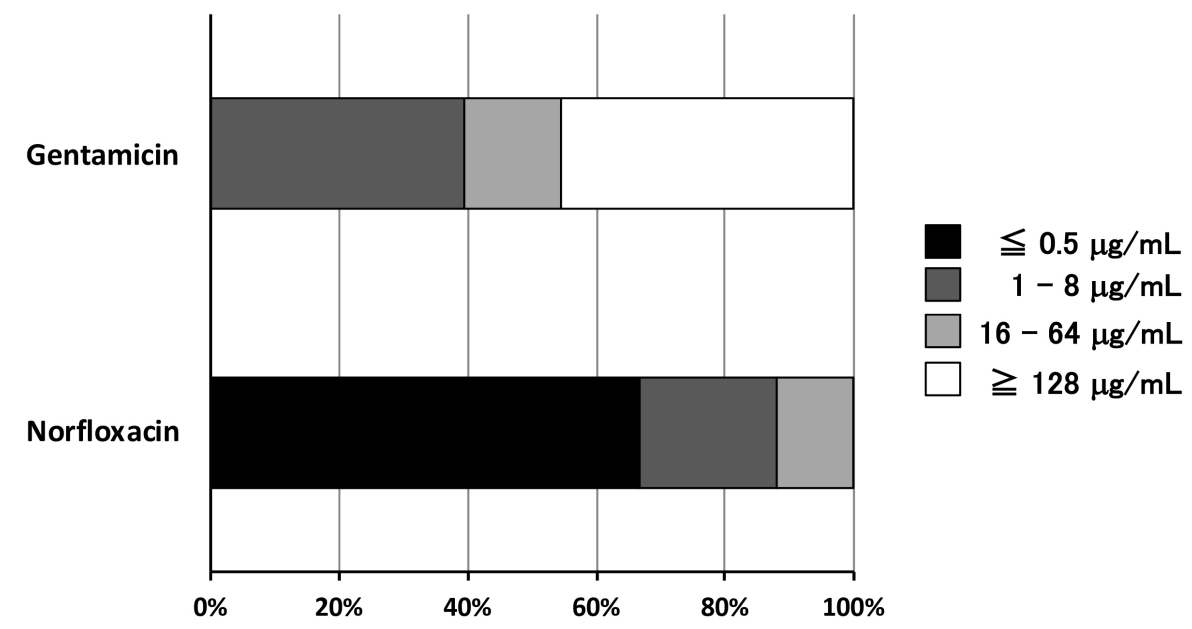

Figure 4. Gentamicin and norfloxacin susceptibility of $S$. aureus strains isolated from patients with atopic dermatitis. The susceptibility of 33 strains of $S$. aureus to each antibiotic was compared in terms of the minimum inhibitory concentration (MIC). The numbers of $S$. aureus strains affected at each MIC are expressed as a percentage of the 33 strains overall.

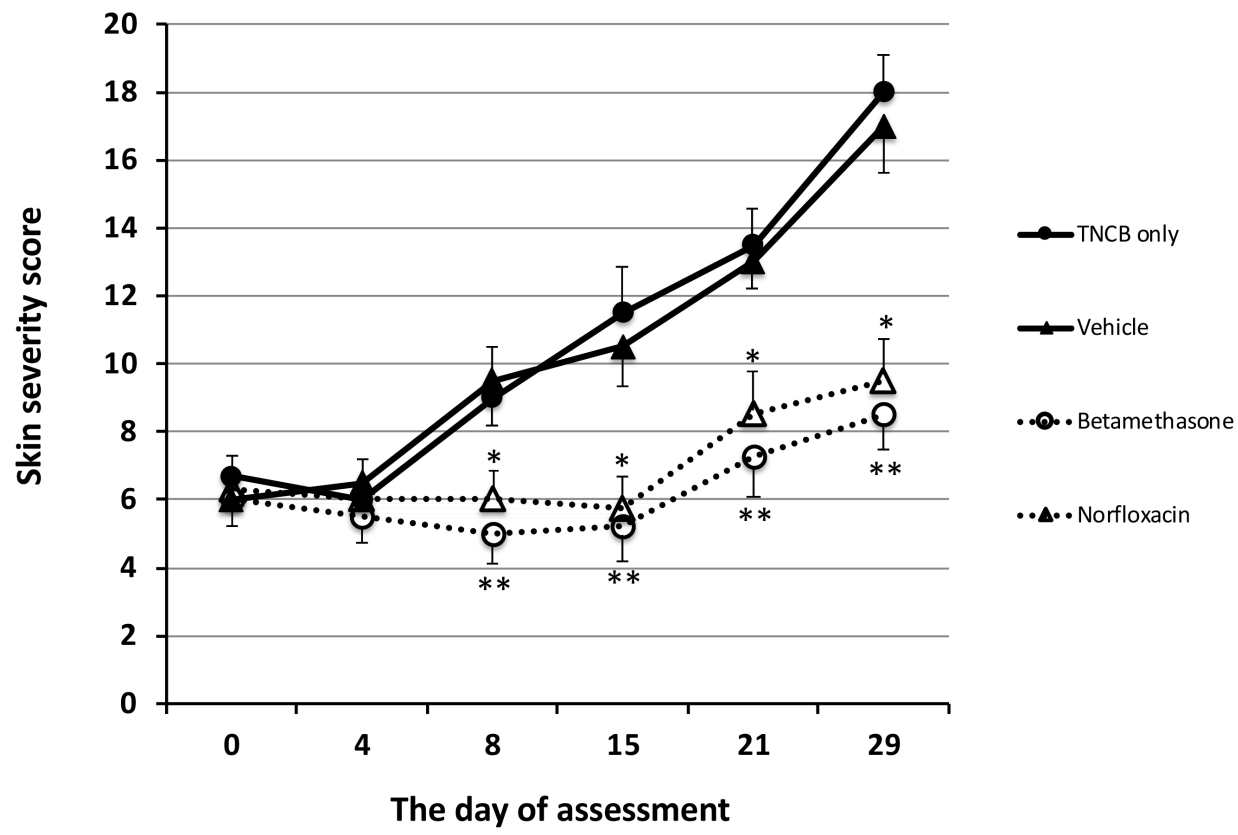

Figure 5. Effects of topical application of betamethasone and norfloxacin on skin severity score. The results for each experimental group are expressed as means $\pm \mathrm{SD}(\mathrm{n}=6)$. $* P<0.01$, $* * P<0.01$ versus TNCB only. 

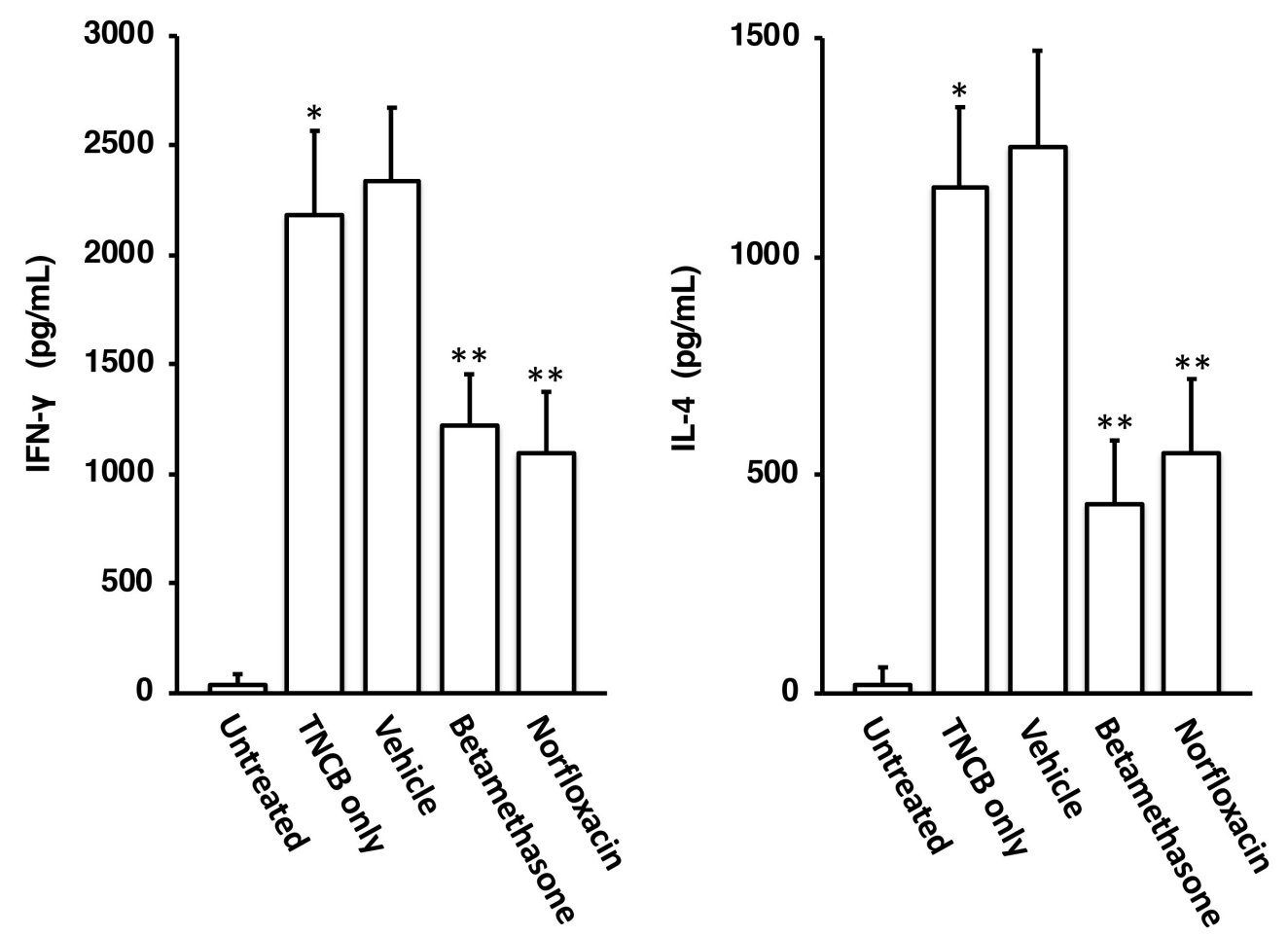

Figure 6. Effects of topical application of betamethasone and norfloxacin on Th1 cell and Th2 cell development in auricular lymph node of NC/Nga mice with AD-like skin lesions. Auricular lymph node cells on the 29th day of assessment of skin severity were stimulated through their surface CD3/CD28 molecules, and the IFN- $\gamma$ and IL-4 concentrations in the culture supernatants were determined by ELISA. Each culture was prepared in triplicate, and the mean value was obtained as a representative result for one experiment. The results are expressed as means $\pm \operatorname{SD}(n=6)$. $* P<0.01$ versus untreated, $* * P<0.01$ versus TNCB only.

\section{DISCUSSION}

Th1/Th2 immune balance lies at the basis of various immunological diseases, including allergy. It has been widely demonstrated that Th2 immunity is responsible for allergic responses and the subsequent pathogenesis of allergic inflammation $(19,20)$. AD is one such allergic disease, and Th2 cells are markedly increased in the peripheral blood and acute skin lesions of AD patients (1). It has been proposed that Th2-type immune responses play a key role in the pathogenesis of $\mathrm{AD}$, and this is supported by the presence of blood eosinophilia and enhanced serum levels of IgE in most affected patients (21). Therefore, the development of Th2 cells is considered to play an important causative role in AD. Our previous study demonstrated that drugs inhibiting Th2 cell development through LCs were therapeutically useful for $\mathrm{AD}$ (18).

In the present study, the effects of 9 fluoroquinolone antibiotics on the level of TIM-4 expression in LCs were investigated. TIM-4 is expressed by DCs including LCs, and its ligand, TIM-1, is expressed by T cells. TIM-4 has been found to be a critical regulator of Th2 cell differentiation and is a good indicator of Th2 cell development through LCs $(17,22)$. The present results showed that only norfloxacin inhibited the expression of TIM-4 in LCs and predicted that norfloxacin might suppress Th2 cell development through LCs. Therefore, LCs were treated with norfloxacin and injected to the hind footpads of mice. As expected, norfloxacin-treated LCs induced suppression of Th2 cell development in lymph node cells of the mice. We also observed that norfloxacin-treated LCs induced suppression of Th1 cell development. Since norfloxacin was washed out before LCs were injected, it was reasonable to assume that norfloxacin acted on LCs and changed their function.

To clarify the mechanism responsible for this down-regulation of Th1 cell development, expression of cell surface molecules other than TIM-4 on LCs was examined. It is known that CD40 promotes the production of IL-12 from APCs and induces Th1 differentiation (23). Interaction between the CD80 and CD86 molecules on APCs and CD28 on Th cells delivers a second signal to Th cells, resulting in promotion of Th1 cell and Th2 cell development (13). In mammals, four 
Notch receptors, Notch 1-4, and five Notch ligands, Delta1, Delta 3, Delta 4, Jagged 1 and Jagged 2, have been identified (24). Amsen et al. (25) have presented evidence that different Notch ligands expressed on APCs direct Th1/Th2 cell differentiation in mice and have concluded that Th1 adjuvant induces Thl differentiation through the expression of Delta members in APCs. Our present study showed that mRNA for CD40, CD80, CD86, Delta 1 and Delta 4 was expressed spontaneously in LCs, and that CD40 mRNA expression was suppressed by treatment with norfloxacin. Therefore, the inhibition of Th1 cell development through norfloxacin-treated LCs would be explained by inhibition of CD40 expression on LCs. The Th2 cytokine response is known to be dominant in the acute phase of $\mathrm{AD}$, and in the late phase the Th1 cytokine response is increased in addition to the Th2 cytokine response, thus contributing to chronic inflammation $(1,21$, 26). These observations indicate that topical application of norfloxacin can regulate both acute and chronic inflammation. In fact, we confirmed that topical application of norfloxacin markedly ameliorated $\mathrm{AD}$-like skin lesions in $\mathrm{NC} / \mathrm{Ng}$ mice over a long period from the acute phase to the late phase. Furthermore, it was confirmed that the development of Th1 and Th2 cells in $\mathrm{NC} / \mathrm{Ng}$ mice after treatment with norfloxacin was significantly inhibited compared with a vehicle control group.

Since the skin of most AD patients shows superficial $S$. aureus colonization and barrier disruption due to a decrease of filaggrin (27), bacterial products such as staphylococcal enterotoxins, lipoteichoic acid and peptidoglycan would penetrate the skin and exacerbate inflammation through Th2 cell development and chemokine production $(1,4-6,28)$. Our present data suggest that norfloxacin has superior ability to inhibit the development of Th1 and Th2 cells in $\mathrm{AD}$ patients, and that $S$. aureus strains isolated from the lesional skin of AD patients are more susceptible to norfloxacin than to gentamicin, which is used widely in Japan for treatment of AD in combination with topical steroids. Therefore, norfloxacin appears to be unique in possessing both antibacterial action against $S$. aureus and being able to control Th1 cell and Th2 cell development.

\section{CONCLUSUIONS}

Topical application of norfloxacin is expected to have superior bactericidal action against $S$. aureus, an inhibitory effect against the subsequent Th2 immune response, and a capacity to control allergen-specific Th1 and Th2 cell development mediated by LCs, unlike the immunosuppressant tacrolimus or steroids. As application of norfloxacin to the skin is considered to be associated with minimal side effects, it might be possible to increase its concentration in ointment to one that would inhibit the Th1 and Th2 immune response in $\mathrm{AD}$ lesions. Thus, topical administration of norfloxacin appears to show promise as a new therapeutic strategy for $\mathrm{AD}$ lesions with superficial $S$. aureus colonization.

\section{ACKNOWLEDGEMENTS}

This work was supported by JSPS KAKENHI Grant Number 17K08469.

\section{CONFLICTS OF INTEREST}

The authors have no conflicts of interest to declare.

\section{REFERENCES}

1. Leung DY, Boguniewicz M, Howell MD, Nomura I, Hamid QA. New insights into atopic dermatitis. J Clin Invest, 2004; 113: 651-657.

DOI: $10.1172 / J C I 21060$

2. Guzik TJ, Bzowska M, Kasprowicz A, Czerniawska-Mysik G, Wójcik K, Szmyd D, Adamek-Guzik T, Pryjma J. Persistent skin colonization with Staphylococcus aureus in atopic dermatitis: relationship to clinical and immunological parameters. Clin Exp Allergy, 2005; 35: 448-455.

DOI: $10.1111 /$ j.1365-2222.2005.02210.x

3. Matsui K, Nishikawa A, Suto H, Tsuboi R, Ogawa H. Comparative study of Staphylococcus aureus isolated from lesional and non-lesional skin of atopic dermatitis. Microbiol Immunol, 2000; 44: 945-947.

DOI: 10.1111/j.1348-0421.2000.tb02587.x

4. Matsui K, Nishikawa A. Peptidoglycan from Staphylococcus aureus induces Th2 immune response in mice. J Investig Allergol Clin Immunol, 2012; 22: 80-86.

5. Matsui K, Nishikawa A. Peptidoglycan-induced T helper 2 immune response in mouse involves interleukin-10 secretion from Langerhans cells. Microbiol Immunol, 2013; 57: 130-138.

DOI: $10.1111 /$ j.1348-0421.2012.12006.x

6. Matsui K, Ikeda R. Peptidoglycan in combination with muramyldipeptide synergistically induces an interleukin-10-dependent $\mathrm{T}$ helper 2-dominant immune response. Microbiol Immunol, 2014; 58: 260-265.

DOI: $10.1111 / 1348-0421.12139$

7. Banchereau J, Steinman RM. Dendritic cells and the control of immunity. Nature, 1998; 392: 245-252.

DOI: $10.1038 / 32588$

8. Katz SI, Tamaki K, Sachs DH. Epidermal 
Langerhans cells are derived from cells originating in bone marrow. Nature, 1979; 282: 324-326.

9. De Fraissinette A, Schmitt D, Thivolet J. Langerhans cells of human mucosa. J Dermatol, 1989; 16: 255-262.

DOI: 10.1111/j.1346-8138.1989.tb01261.x

10. Barrett AW, Cruchley AT, Williams DM. Oral mucosal Langerhans' cells. Crit Rev Oral Biol Med, 1996; 7: 36-58.

11. MacPherson GG, Liu LM. Dendritic cells and Langerhans cells in the uptake of mucosal antigens. Curr Top Microbiol Immunol, 1999; 236: 33-53.

12. Steinman R, Inaba K. Immunogenicity: role of dendritic cells. Bioessays, 1989; 10: 145-152. DOI: $10.1002 /$ bies.950100503

13. Lanzavecchia A, Sallusto $F$. Dynamics of $T$ lymphocyte responses: intermediates, effectors, and memory cells. Science, 2000; 290: 92-97.

DOI: $10.1126 /$ science.290.5489.92

14. Okamoto $\mathrm{T}$, Iwata $\mathrm{S}$, Ohnuma $\mathrm{K}$, Dang $\mathrm{NH}$, Morimoto C. Histamine H1-receptor antagonists with immunomodulating activities: potential use for modulating $\mathrm{T}$ helper type 1 (Th1)/Th2 cytokine imbalance and inflammatory responses in allergic diseases. Clin Exp Immunol, 2009; 157: 27-34. DOI: $10.1111 / \mathrm{j} .1365-2249.2009 .03958 . x$

15. Matsui K, Mori A, Ikeda R. Langerhans cell-like dendritic cells stimulated with an adjuvant direct the development of Th1 and Th2 cells in vivo. Clin Exp Immunol, 2015; 182: 101-107. DOI: $10.1111 /$ cei. 12671

16. Dalhoff A, Shalit I. Immunomodulatory effects of quinolones. Lancet Infect Dis, 2003; 3: 359-371. DOI: 10.1016/S1473-3099(03)00658-3

17. Matsui K, Tamai S, Ikeda R. Effects of macrolide antibiotics on Th1 cell and Th2 cell development mediated by Langerhans cells. J Pharm Pharm Sci, 2016; 19: 357-366.

DOI: $10.18433 / \mathrm{J} 3 \mathrm{Z} 32 \mathrm{~F}$

18. Matsui K, Tachioka K, Onodera K, Ikeda R. Topical application of josamycin inhibits development of atopic dermatitis-like skin lesions in NC/Nga mice. J Pharm Pharm Sci, 2017; 20: 38-47. DOI: $10.18433 / J 3 G W 3 D$

19. Herrick CA, Bottomly K. To respond or not to respond: $\mathrm{T}$ cells in allergic asthma. Nat Rev Immunol, 2003; 3: 405-412.

DOI: $10.1038 /$ nri1084

20. Kay AB. Advances in immunology: allergy and allergic diseases - first of two parts. N Engl J Med, 2001; 344: 30-37.

DOI: $10.1056 /$ NEJM200101043440106

21. Grewe M, Bruijnzeel-Koomen CAFM, Schöpf E, Thepen T, Langeveld-Wildschut AG, Ruzicka T, Krutmann J. A role of Th1 and Th2 cells in the immunopathogenesis of atopic dermatitis. Immunol Today, 1998; 19: 359-361.

DOI: $10.1016 / \mathrm{S} 0167-5699(98) 01285-7$

22. Ruiter B, Shreffler WG. The role of dendritic cells in food allergy. J Allergy Clin Immunol, 2012; 129: 921-928.
DOI: $10.1016 /$ j.jaci.2012.01.080

23. Van Kooten C, Banchereau J. CD40-CD40 ligand. J Leukoc Biol, 2000; 67: 2-17.

DOI: $10.1002 / \mathrm{jlb} .67 .1 .2$

24. Artavanis-Tsakonas S, Rand MD, Lake RJ. Notch signaling: cell fate control and signal integration in development. Science, 1999; 284: 770-776.

DOI: $10.1126 /$ science.284.5415.770

25. Amsen D, Blander JM, Lee GR, Tanigaki K, Honjo T, Flavell RA. Instruction of distinct CD4 T helper cell fates by different Notch ligands on antigen-presenting cells. Cell, 2004; 117: 515-526. DOI: $10.1016 / \mathrm{S} 0092-8674(04) 00451-9$

26. Sabin BR, Peters N, Peters AT. Chapter 20: atopic dermatitis. Allergy Asthma Proc, 2012; 33 (Suppl 1): S67-69. DOI: $10.2500 /$ aap.2012.33.3553

27. Brown SJ, McLean WH. One remarkable molecule: filaggrin. J Invest Dermatol, 2012; 132: 751-762. DOI: $10.1038 /$ jid.2011.393

28. Matsui K, Nishikawa A. Lipoteichoic acid from Staphylococcus aureus induces Th2-prone dermatitis in mice sensitized percutaneously with an allergen. Clin Exp Allergy, 2002; 32: 783-788.

DOI: $10.1046 / \mathrm{j} .1365-2222.2002 .01357 . \mathrm{x}$ 